\title{
Synthesis and characterization of cobalt nitroprusside nano particles: Application to sulfite sensing in food and water samples
}

\author{
Samrat Devaramani, Pandurangappa Malingappa* \\ Department of Studies in Chemistry, Central College Campus, Ambedkar Veedhi, Bangalore University, Bangalore 560001, India
}

\section{A R T I C L E I N F O}

\section{Article history:}

Received 25 May 2012

Received in revised form 21 August 2012

Accepted 24 August 2012

Available online 6 September 2012

\section{Keywords:}

Cobalt nitroprusside nano particles

Modified carbon paste electrode

Sulfite

Cyclic voltammetry

Food sample

\begin{abstract}
A B S T R A C T
A new protocol toward the synthesis of cobalt nitroprusside (CoNP) coordination nanoparticles has been described based on drop-by-drop (DbD) method without using any additives. It was also prepared by sonication as well as bulk mixing methods for comparison purpose. The prepared complex was characterized by Infrared spectroscopy (FTIR), XRD and cyclicvoltammetry (CV) techniques. The CoNP complexes prepared by different synthetic approaches were used as modifier molecules to fabricate carbon paste electrodes (CPE's) toward electrochemical oxidation of sulfite. The experimental results revealed that the cobalt nitroprusside nanoparticles ( $\mathrm{n}$-CoNP) prepared by drop-by-drop method showed a considerable enhancement in the electrocatalytic activity when compared to its counterparts prepared by other approaches. Electrochemical behavior of the n-CoNP CPE was studied and used as an electrochemical sensor for the quantification of sulfite at trace level. It showed a linear response over the concentration range 1-5.9 $\times 10^{-5} \mathrm{M}$ and $2-8 \times 10^{-3} \mathrm{M}$ of sulfite. The limit of detection and limit of quantification were found to be $0.4 \times 10^{-5} \mathrm{M}$ and $2.29 \times 10^{-5} \mathrm{M}$ respectively. The interference of various organic acids and inorganic ions commonly present in different food and water sample matrices were studied. The n-CoNP modified electrode was used for the quantification of sulfite in different food samples and the results were in good agreement with those obtained by the standard iodometric protocol.
\end{abstract}

(c) 2012 Elsevier Ltd. All rights reserved.

\section{Introduction}

Polycyanide metal complexing reagents, with a general formula $\left[\mathrm{M}(\mathrm{CN})_{5} \mathrm{~L}\right]^{n-}$ where $\mathrm{M}=\mathrm{Fe}, \mathrm{Ru}$, Os and $\mathrm{L}$ a variable ligand $\left(\mathrm{H}_{2} \mathrm{O}, \mathrm{CN}^{-}, \mathrm{NH}_{3}\right.$, amines, $\mathrm{NO}, \mathrm{NO}_{2}^{-}, \mathrm{N}$-heterocyclic molecules, $\mathrm{CO}$, etc.) has received much attention and systematic investigation of their electronic structure and reactivity are persuaded [1]. Pentacyanonitrosylferrate $\left[\mathrm{Fe}(\mathrm{CN})_{5} \mathrm{NO}\right]^{2-}$ is also referred as nitroprusside (NP) is one of the important ligands of the above mentioned family because of its ability to complex with various transitional metal ions. Metal nitroprussides (MNP) have received great attention of the scientific community as electrochemical sensors recently due to its versatility and electrocatalytic activity [2-6]. MNP complexes where $\mathrm{M}=\mathrm{Sn}, \mathrm{Ni}, \mathrm{Zn}, \mathrm{Cd}, \mathrm{Co}, \mathrm{Pb}$, etc. were prepared as thin films on the surface of various electrodes using different strategies and successfully used for the quantification of wide range of analytes like ascorbic acid, hydrazine, L-cysteine, hydrogen peroxide, sulfide, sulfite, etc. [2,3,7-12]. In recent years carbon paste electrodes (CPE) have been extensively used over surface modified rigid electrodes for the determination

\footnotetext{
* Corresponding author. Tel.: +91 8022961352.

E-mail address: mprangachem@gmail.com (P. Malingappa).
}

of wide range of analytes due to their easy fabrication, wide potential window, easy surface renewability and low residual currents [13].

Nano scale sized metallic particles are attracting considerable attention for their intriguing properties and potential applications [14]. Recently, materials in the nanometer range have shown superior or advantageous functional properties for a wide range of technological applications, including catalysis, optics, microelectronics, and chemical/biological sensors. Metal nanoparticles as catalysts have been vigorously investigated because of their specific properties such as large surface area and their superior properties which are different from their bulk counterparts [15]. Inorganic nanoparticles are very useful candidates for electrochemical studies owing to their outstanding activity and catalytic power [16-18]. The large surface-to-volume ratio and the active sites of these nano-sized metal particles in electrocatalysis constitute a part of the driving force in developing the nanosized electrocatalysts. The application of the carbon paste electrodes modified with nanostructures exhibit considerable improvement in the electrochemical behavior of compounds $[19,20]$. The presence of nanoparticles in electrochemical sensors can decrease the over-potentials of many analytes at common unmodified electrodes. In particular, these analytical devices when modified with metal nanoparticles 
have attracted a remarkable interest to realize electrochemical sensors.

Sulfite is well known for its use in food and beverage industries as a preservative. Sulfite prevents oxidation, inhibit bacterial growth, enzyme activity causing browning and to inhibit the growth of microorganisms during storage [21]. Despite these great advantages, the sulfite content in food and beverages should be strictly limited due to its potential toxicity and harmful effects toward hypersensitive people. Before 1986 sulfites were considered incorrectly harmless for consumers and they received the "Generally Recognized As Safe" (GRAS) status. In the same year US Food and Drug Administration (FDA) revoked the GRAS status and required sulfite declaration on the label of any food item containing $10 \mathrm{ppm}$ levels of sulfite [22]. Sulfite is considered as one among the well known food allergens. Sulfite hypersensitivity is usually, but not exclusively, found within the chronic asthmatic population. Adverse reactions to sulfites in nonasthmatics are extremely rare. Asthmatics who are steroid-dependent or who have a higher degree of airway hyper reactivity may be at greater risk of experiencing a reaction to sulfite-containing foods. Even within this limited population, sulfite sensitivity reactions vary widely, ranging from no reaction to severe. These manifestations may include dermatological, respiratory or gastrointestinal symptoms $[23,24]$. In order to quantify such trace level sulfite there is a significant progress in its quantification technology. Several methods have been reported for the quantification of sulfite from a variety of sample matrices [21]. These methods are mainly based on techniques like electrochemical [25-33], biosensors [34], chromatography [35], chemiluminescence [36-38] and spectrophotometry [39]. Among these, electrochemical methods find widespread use due to their simplicity, easy modification and easy adoptability. Chemically modified electrodes (CMEs) have become significant ones in recent years due to their tailoring made properties which imparts selectivity as well as analyte specificity.

Pouranghi-Azar and Sabzi [40] have used the glassy carbon electrode electrochemically modified with CoNP complex to oxidize sulfite. A pioneering work on the synthesis of cyano-bridged coordination polymer nano objects like Prussian blue and its analogues have been reported in recent years [41,42]. Different techniques such as reverse micelle, ionic liquid by using stabilizing ligands in solution have been developed to prepare metal nanoparticles [43-45]. Very few reports appeared on the direct synthesis of Prussian blue analogue nanoparticles without any templating and/or additives $[46,47]$.

In most of the earlier mentioned protocols metal nitroprussides are electrochemically coated onto the rigid electrode surface and it has been used as an electrochemical sensor. The surface renewal is quite cumbersome in all these rigid surface modified electrochemical sensors. In order to overcome the surface renewability problem of this type of electrodes, an attempt has been made for the first time to synthesize CoNP nanoparticles in solution phase without any additives. Then the synthesized CoNP nano particles have been used as a modifier in designing an electrochemical sensor for the sulfite quantification. The proposed sensor has been successfully applied for the measurement of sulfite from a variety of food stuff and water samples.

\section{Experimental}

\subsection{Apparatus}

All the samples were characterized by X-ray diffraction (Bruker aXS Model D8 Advance powder X-ray diffractometer, $\mathrm{Cu}$ K $\alpha$ source $\lambda=15.418 \mathrm{~nm}, \theta-2 \theta$ geometry). IR spectra were recorded using a Bruker Alpha-T FTIR spectrometer (Diamond crystal ATR mode, resolution $\left.4 \mathrm{~cm}^{-1}, 400-4000 \mathrm{~cm}^{-1}\right)$. Scanning electron micrographs were obtained using Quanta-200 scanning electron microscope by dispersing sample conducting carbon tape and sputter coating with gold to improve the conductivity.

Cyclic voltammetry experiments were performed using $\mathrm{CH}$ Instruments electrochemical work station (Model CHI 619B, CH Instruments, TX, USA) in a standard three electrode cell. A carbon paste electrode as a working electrode, Pt wire as the counter electrode and $\mathrm{Ag} / \mathrm{AgCl}$ served as the reference electrode.

\subsection{Chemicals and reagents}

Sodium sulfite $\mathrm{Na}_{2} \mathrm{SO}_{3}$, cobalt chloride hexahydrate $\mathrm{CoCl}_{2} \cdot 6 \mathrm{H}_{2} \mathrm{O}$, sodium nitroprusside dihydrate $\mathrm{Na}_{2}\left[\mathrm{Fe}(\mathrm{CN})_{5} \mathrm{NO}\right]$ $.2 \mathrm{H}_{2} \mathrm{O}$, potassium chloride $\mathrm{KCl}$ were all analytical grade and were used as received. Potassium nitrate $\mathrm{KNO}_{3}(0.5 \mathrm{M})$ was prepared using $0.05 \mathrm{M}$ acetic acid-0.05 $\mathrm{M}$ sodium acetate buffer solution of $\mathrm{pH}$ 5. All solutions were prepared using double distilled water.

\subsection{Synthesis of cobalt pentacyanonitrosylferrate}

CoNP was synthesized by precipitation using three different procedures: Drop by drop, sonication and bulk mixing at a temperature of $5-10^{\circ} \mathrm{C}$.

Drop by drop (DbD) method: $10 \mathrm{ml}$ aqueous solution of $0.01 \mathrm{M}$ sodium nitroprusside was taken in a dropping funnel and it was added dropwise to $10 \mathrm{ml}$ of $0.02 \mathrm{M}$ aqueous solution of cobalt chloride taken in a beaker which was thermostated at $5-10^{\circ} \mathrm{C}$ under vigorous stirring. The solution turns turbid due to the formation of cobalt nitroprusside complex. It is referred as n-CoNP in all further studies.

Sonication method: $10 \mathrm{ml}$ each of aqueous solutions of $0.01 \mathrm{M}$ cobalt nitroprusside and $0.02 \mathrm{M}$ cobalt chloride were mixed at $5-10^{\circ} \mathrm{C}$ and sonicated for $30 \mathrm{~min}$. It is designated as s-CoNP.

Bulk mixing method: In this method, $10 \mathrm{ml}$ of aqueous solutions of $0.01 \mathrm{M}$ sodium nitroprusside and $0.02 \mathrm{M}$ cobalt chloride which were maintained at $5-10^{\circ} \mathrm{C}$ were mixed immediately in a beaker. The resulting compound has been designated as b-CoNP.

In all the three cases, the $\mathrm{pH}$ of the solutions were maintained in acidic condition to avoid the formation of metal hydroxides and the resultant precipitates were left overnight without disturbing. After $24 \mathrm{~h}$ the supernatant liquid was decanted and the residue was centrifuged. The prepared CoNP compound was initially washed with plenty of water then finally with alcohol. The residue was collected in a petridish and dried at room temperature. The resulted CoNP particles from all the three procedures were used as a modifier in fabricating carbon paste electrodes.

\subsection{Electrode preparation}

The modified carbon paste electrode was prepared manually by thoroughly mixing the dispersed graphite powder with n-CoNP at $15: 1$ mass ratio and subsequently adding $38 \%(\mathrm{~m} / \mathrm{m})$ of mineral oil. The resultant mixture was ground in an agate mortar for $10-15 \mathrm{~min}$. The obtained paste was packed into the capillary tube from the wider end. A copper wire was inserted from the opposite end of the capillary to obtain the electrical contact. Similarly b-CoNP and s-CoNP modified CPE electrodes were prepared. Bare carbon paste electrode was prepared by following the above procedure. All these electrodes were dried for $24 \mathrm{~h}$ at room temp and the resistivity was measured using a multimeter, which has been found to be $10-12 \Omega$.

\section{Results and discussion}

Cobalt nitroprusside complex has been synthesized from three different approaches. The complex resulted from all the three 

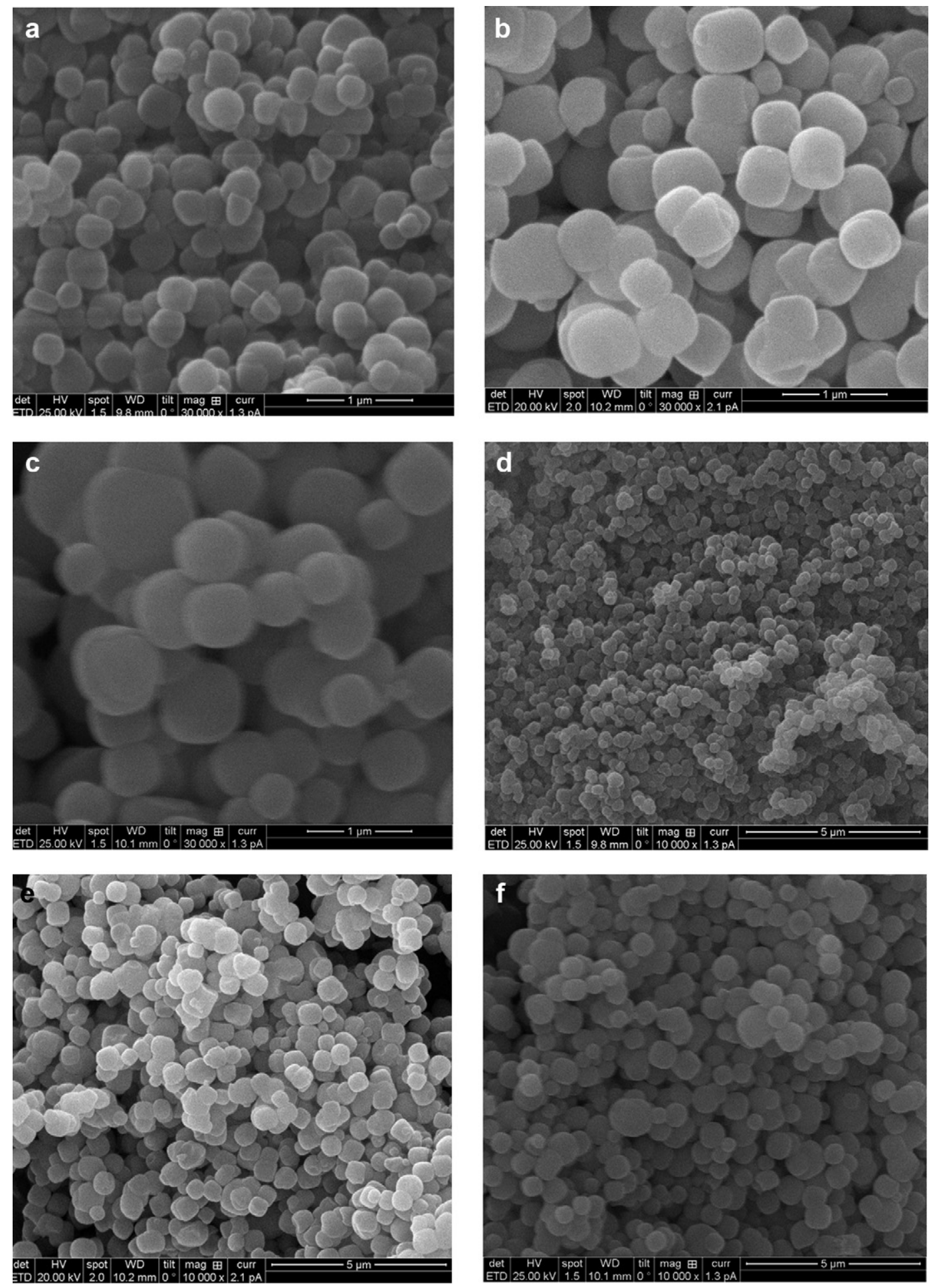

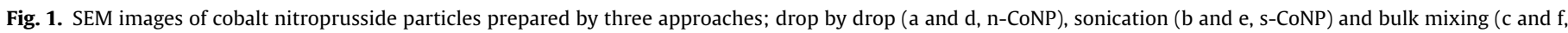
b-CoNP) methods.

approaches has been characterized by the IR spectroscopy to confirm the presence of expected functional groups. The SEM was used to understand the surface morphology and the difference in the grain size and by the XRD pattern to get the information about the phase purity. CPE's were prepared using the entire three CNP complexes to study the electrochemical behavior of the synthesized materials. Then the electrocatalytic activity of the n-CoNP, $\mathrm{s}-\mathrm{CoNP}$ and $\mathrm{b}-\mathrm{CoNP}$ to oxidize the sulfite has been compared using the modified CPEs. The n-CoNP modified CPE showed a better catalytic activity toward the oxidation of sulfite compared to other two CoNP modified CPEs. Scan rate studies have been done to understand the electrode process. Then optimization of electrolyte, $\mathrm{pH}$ and interference of various ions generally present in the food products has been carried out. To check the applicability of the n-CoNP complex, sulfite has been quantified in various food samples using the CPE modified with the same. 


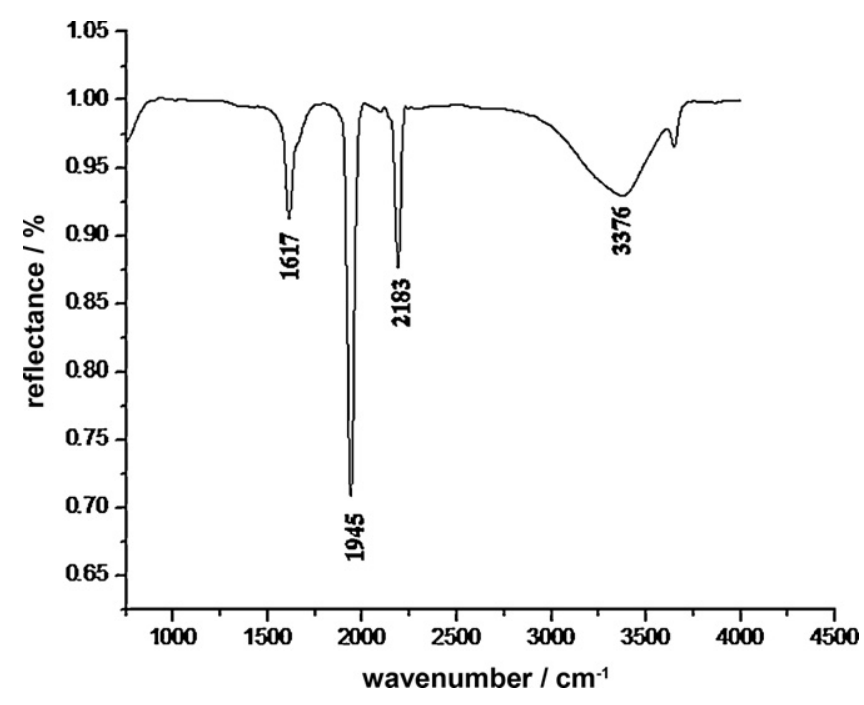

Fig. 2. FTIR spectrum of n-CoNP compound.

\subsection{Surface morphology of cobalt nitroprusside particles}

The morphology and grain sizes of the prepared CoNP particles were studied by recording the SEM images for all the three types. The surface morphology of cobalt nitroprusside particles was of almost same for all the three types. However, they differed in grain sizes. Accordingly the particles of all the three types composed of well dispersed spheres. The n-CoNP contains very small particles, where as s-CoNP comprised of small particles and medium sized particles and more number of bigger particles can be seen in case of b-CoNP. The SEM images are shown in Fig. 1(a)-(f) under two different magnifications.

\subsection{IR study}

The CoNP prepared by drop by drop, sonication and bulk mixing methods were characterized by FTIR spectroscopy technique. The sharp peak at $1617 \mathrm{~cm}^{-1}$ is due to the NO (nitrosyl) stretching vibration. However an intense peak at $2183 \mathrm{~cm}^{-1}$ can be related to the stretching frequency of $\mathrm{CN}$ (cyanide) group. The broad band at $3376 \mathrm{~cm}^{-1}$ was due to $\mathrm{OH}$ (hydroxyl) group stretching vibration. The peaks assigned are in good agreement with the reported literature [48]. These studies revealed that the compound is a hydrated one (Fig. 2).

\subsection{XRD study}

X-ray diffraction was used to identify the phase purity of synthesized CoNP complex. The XRD pattern of the as synthesized sample is shown in Fig. 3. Sharp reflections were observed at $d$-spacing corresponding to the $n$-CoNP phase. The sharp reflections indicate that the as synthesized product is highly crystalline. Same kind of $\mathrm{X}$-ray patterns (Bragg reflections in all the samples were observed at same $2 \theta$ values) were obtained for s-CoNP and b-CoNP (data not shown). The average crystallite size of n-CoNP was calculated using the Scherrer formula and it has been found that the crystallite size varies within $53-55 \mathrm{~nm}$. Obtained XRD pattern of the n-CoNP matches with the crystallographica pdf no. 80-2395.

\subsection{Electrochemical behavior of cobalt nitroprusside modified carbon paste electrode}

Cyclic voltammogram of CoNP CPE's were recorded in the scan range between 0 and $1 \mathrm{~V}$ vs. $\mathrm{Ag} / \mathrm{AgCl}$ electrode in $0.5 \mathrm{M} \mathrm{KNO}_{3}$ as

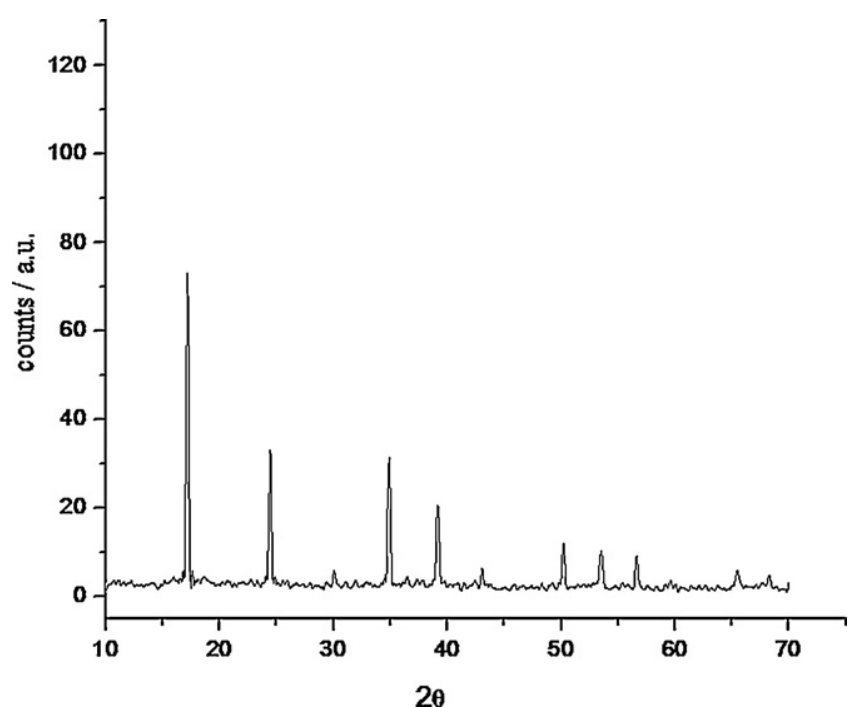

Fig. 3. XRD spectrum of n-CoNP compound.

a supporting electrolyte at a scan rate of $0.5 \mathrm{Vs}^{-1}$ (Fig. 4). The voltammograms exhibit a pair of peaks with a formal potential $E^{\circ}=\left(E_{\mathrm{pa}}+E_{\mathrm{pc}}\right) / 2$ of $0.48,0.54,0.53 \mathrm{~V}$ respectively for n-CoNP, sCoNP, b-CoNP compounds. The peaks are well resolved and the ratio of the anodic to cathodic peak currents were found to be almost unity which indicates that the process is reversible and the peaks are due to $\left[\mathrm{Fe}(\mathrm{II})(\mathrm{CN})_{5} \mathrm{NO}\right] /\left[\mathrm{Fe}(\mathrm{III})(\mathrm{CN})_{5} \mathrm{NO}\right]$ redox couple. The redox potentials of all the CoNP nanoparticles prepared by the three approaches were in good agreement with the literature [2].

The electrocatalytic activity of CoNP particles prepared by the three approaches was examined by studying the cyclic voltammetry in presence of sulfite. The cyclic voltammograms of the three CPE's modified with n-CoNP, s-CoNP and b-CoNP in the absence and presence of $3.4 \mathrm{mM}$ sulfite are shown in Fig. 5. The electrochemical response, i.e. increase in the anodic peak current due to electrocatalytic oxidation of sulfite was considerably greater in case of n-CoNP CPE compared to other two electrodes.

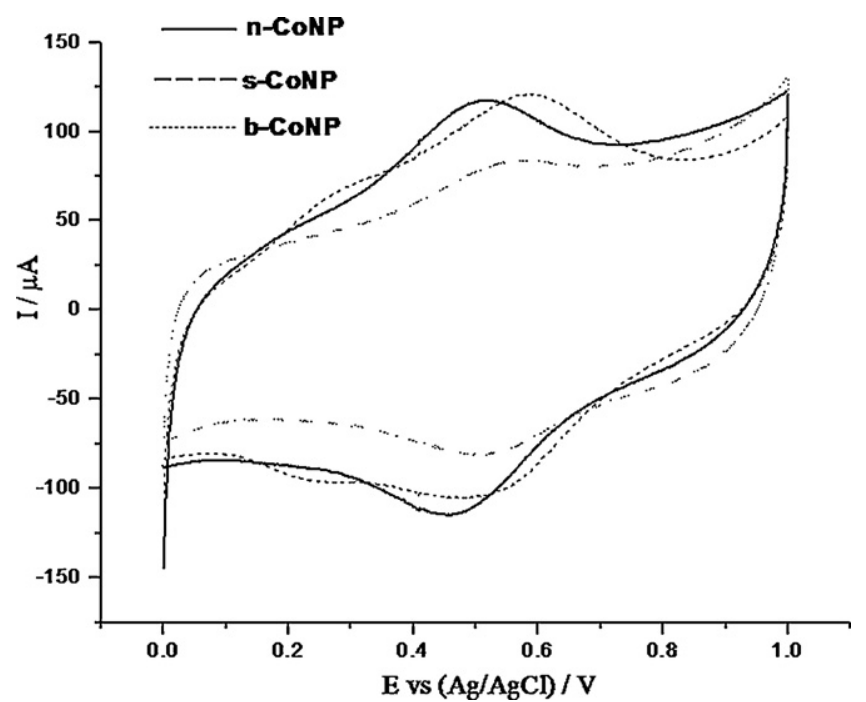

Fig. 4. Cyclic voltammograms of CoNP-modified carbon paste electrodes in $0.5 \mathrm{M}$ $\mathrm{KNO}_{3}$. 

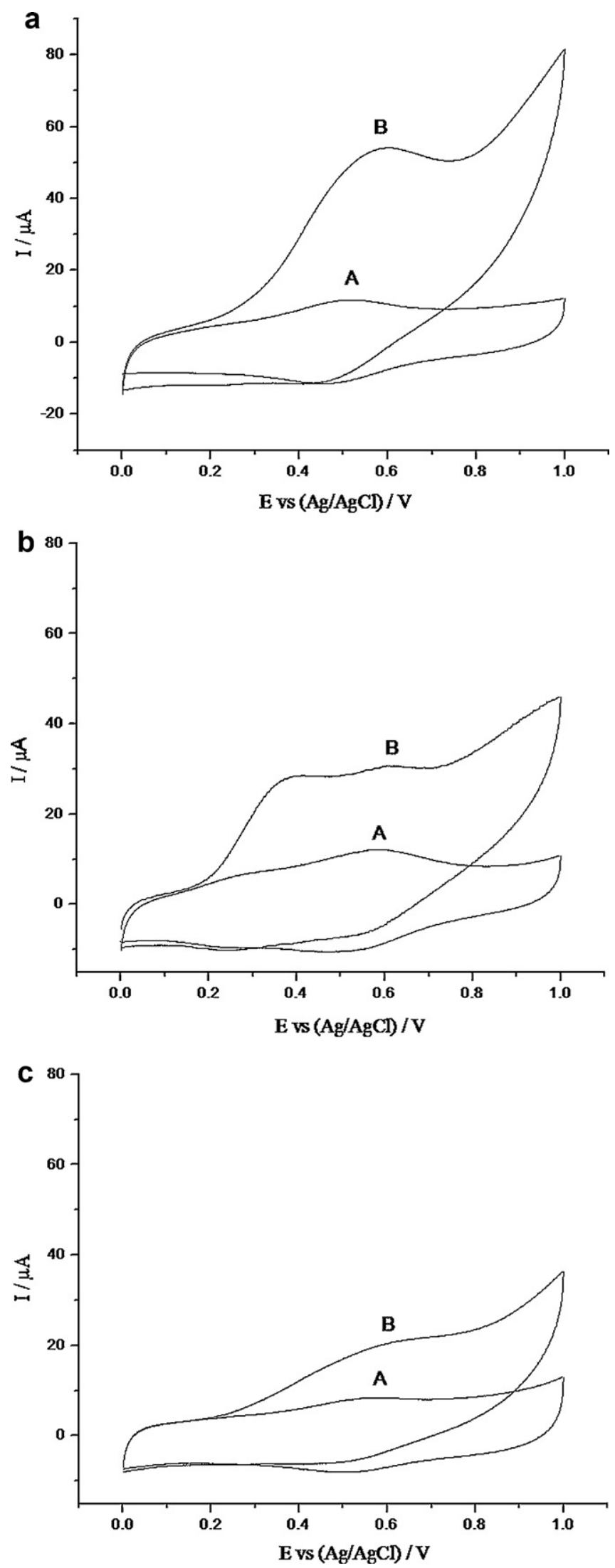

Fig. 5. (a) Cyclic voltammogram of $n-C o N P$ modified CPE (A) in absence of sulfite (B) in presence of $3.4 \mathrm{mM}$ sulfite. (b) Cyclic voltammogram of s-CoNP modified CPE (A) in absence of sulfite (B) in presence of $3.4 \mathrm{mM}$ sulfite. (c) Cyclic voltammogram of b-CoNP modified CPE (A) in absence of sulfite (B) in presence of $3.4 \mathrm{mM}$ sulfite.

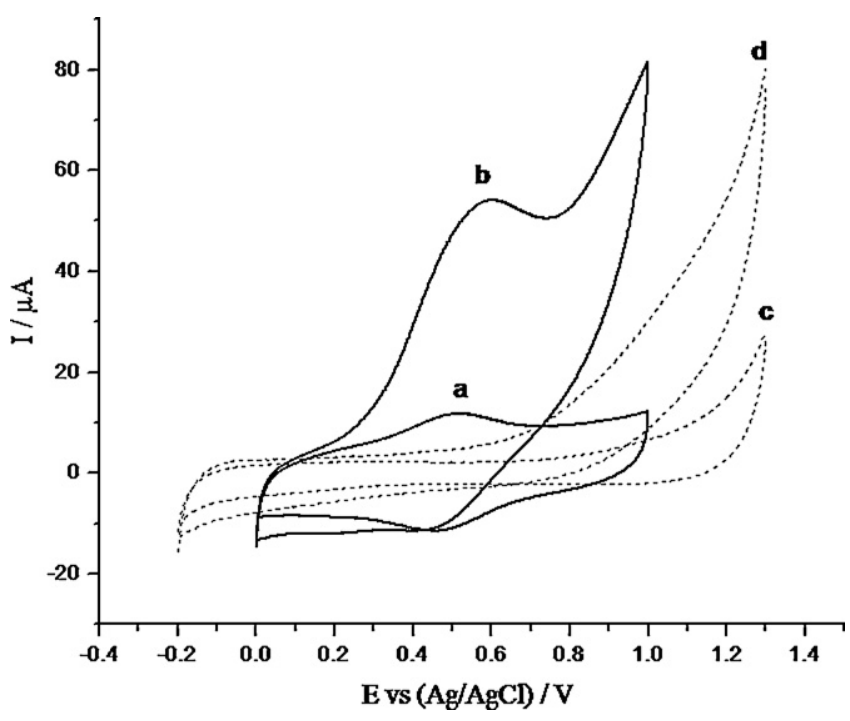

Fig. 6. Cyclic voltammograms of n-CoNP modified CPE in the absence (a) and presence (b) of $3.4 \mathrm{mM}$ sulfite. Cyclic voltammograms of bare CPE in the absence (c) and presence (d) of $3.4 \mathrm{mM}$ sulfite.

\subsection{Electrocatalytic oxidation of sulfite at nano cobalt nitroprusside modified carbon paste electrode}

In order to understand the electrocatalytic activity of n-CoNP $\mathrm{CPE}$, the voltammetric behavior of the electrode in presence of sulfite was compared with that of the bare electrode. Fig. 6 illustrates the overlaid cyclic voltammograms of n-CoNP modified and bare carbon paste electrode in the absence and presence of $3.4 \mathrm{mM}$ sulfite in $0.5 \mathrm{M} \mathrm{KNO}_{3}$ as an electrolyte. It is clear that the presence of CoNP nanoparticles as a modifier in the electrode significantly improves the anodic current of the modified electrode in presence of sulfite. These studies revealed that the modified electrode with n-CoNP spheres acts as an efficient electrocatalyst and improves the analytical performance of the electrode compared to bare electrode. The reaction between the sulfite and modifier molecule is a one electron transfer process and it follows heterogeneous EC catalytic mechanism.

$$
\begin{aligned}
& \mathrm{KCo}\left[\mathrm{Fe}^{\mathrm{II}}(\mathrm{CN})_{5} \mathrm{NO}\right] \quad \rightarrow \quad \mathrm{Co}\left[\mathrm{Fe}^{\mathrm{III}}(\mathrm{CN})_{5} \mathrm{NO}\right]+\mathrm{K}^{+}+\mathrm{e}^{-}(\mathrm{E}) \\
& \uparrow
\end{aligned}
$$

The overall reaction can be expressed as below

$$
\begin{aligned}
& 2 \mathrm{Co}\left[\mathrm{Fe}^{\mathrm{III}}(\mathrm{CN})_{5} \mathrm{NO}\right]+2 \mathrm{~K}^{+}+\mathrm{HSO}_{3}{ }^{-}+\mathrm{H}_{2} \mathrm{O} \rightarrow 2 \mathrm{KCo}\left[\mathrm{Fe}^{\mathrm{II}}(\mathrm{CN})_{5} \mathrm{NO}\right] \\
& +\mathrm{SO}_{4}{ }^{2-}+3 \mathrm{H}^{+}
\end{aligned}
$$

\subsection{Optimization study}

The experimental variables like scan rate, $\mathrm{pH}$ effect and the nature of electrolyte were optimized to get a maximum electrochemical response of the $n-C o N P C P E$.

\subsubsection{Effect of scan rate}

The effect of scan rate was studied by varying the sweep rates from 10 to $1000 \mathrm{mV} \mathrm{s}^{-1}$ (Fig. 7(a)). The peak currents of the voltammogram are linearly related with scan rate upto $100 \mathrm{mV} \mathrm{s}^{-1}$ (Fig. 7(b)) indicating that the process is surface confined redox reaction. However at high scan rates, i.e. above $100 \mathrm{mV} \mathrm{s}^{-1}$ the peak currents were proportional to the square root of scan rate (Fig. 7(c)) 

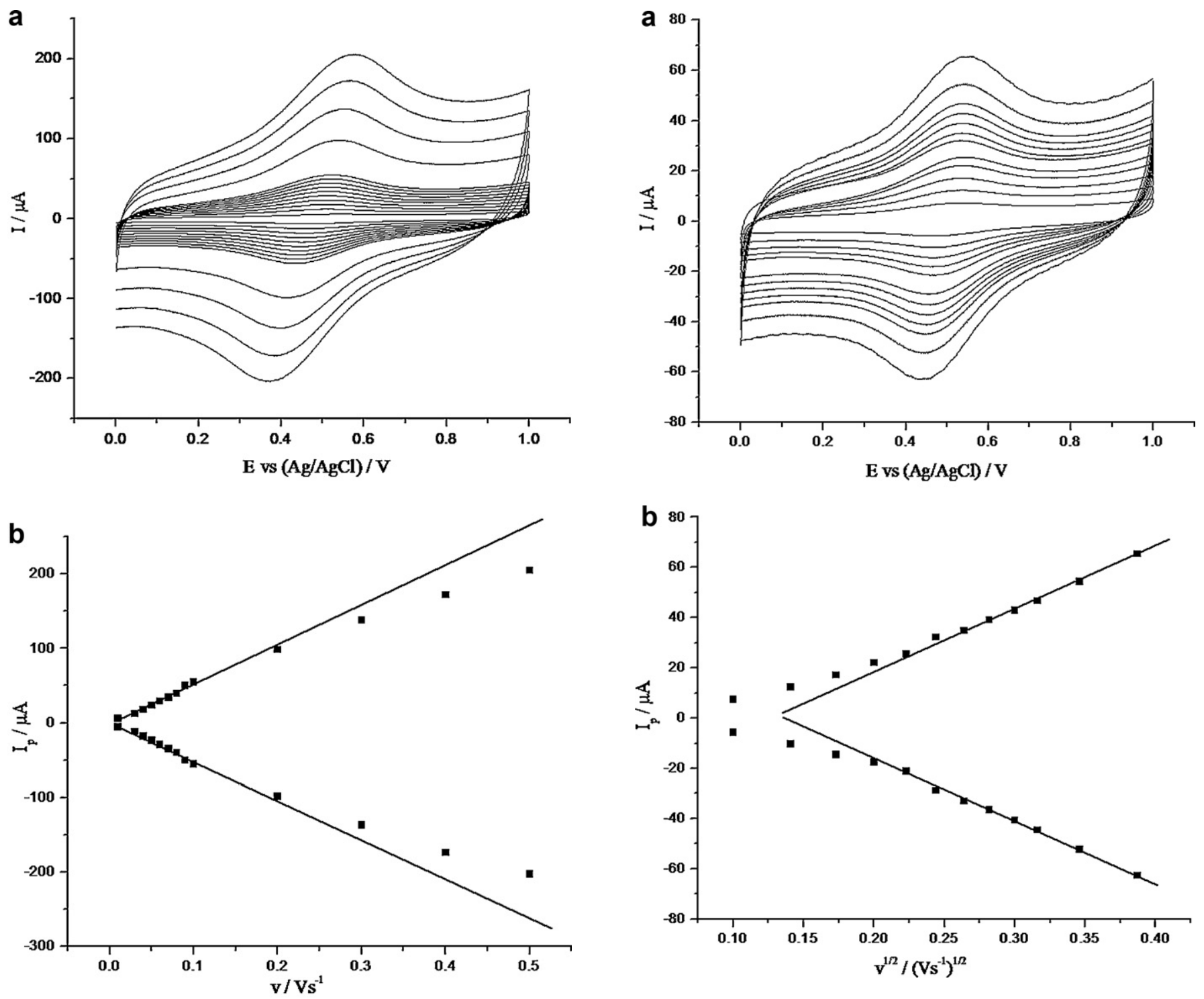

Fig. 8. (a) Overlaid cyclic voltammograms of n-CoNP CPE at different scan rates in presence of $1 \mathrm{mM}$ sulfite and (b) plot of current vs. square root of scan rate.

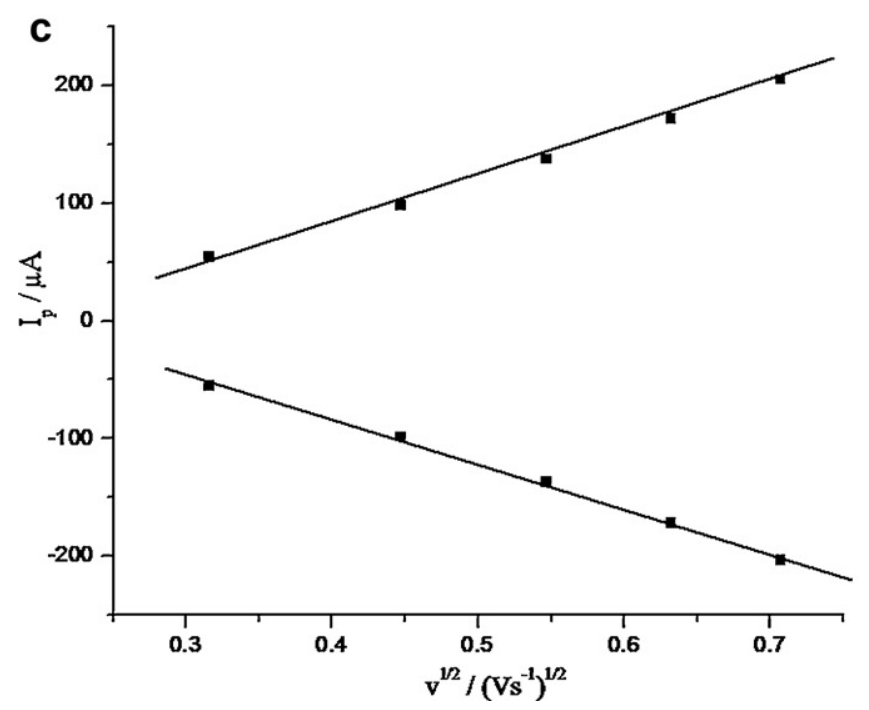

Fig. 7. (a) Overlaid cyclic voltammograms of $n-C o N P C P E$ in $0.5 \mathrm{M} \mathrm{KNO}_{3}$ at varied scan rates, (b) plot of current vs. scan rate and (c) plot of current vs. square root of scan rate of n-CoNP CPE in $0.5 \mathrm{M} \mathrm{KNO}_{3}$.

this means the process is diffusion controlled. It can be assumed due to relative slow diffusion of cations into a limited reaction layer. The ratio of $I_{\mathrm{pa}}$ and $I_{\mathrm{pc}}$ remains almost equal to unity at different scan rates indicating that the reaction is surface bound in nature.

Fig. 8(a) shows the cyclic voltammograms of n-CoNP modified carbon paste electrode in $0.5 \mathrm{M} \mathrm{KNO}_{3}$ solution at different scan rates in the presence of $1 \mathrm{mM}$ sulfite. Linear dependence of the peak currents, $I_{\mathrm{pa}}$ and $I_{\mathrm{pc}}$ on the square root of scan rate was obtained (Fig. 8(b)). This indicates that the electrode process is controlled by mass diffusion which is suitable behavior for quantitative application.

\subsubsection{Effect of $p H$}

The effect of $\mathrm{pH}$ on the electrochemical behavior of $\mathrm{n}$-CoNP modified electrode was studied by varying the electrolyte $\mathrm{pH}$ values ranging from 1 to 8 . In all cases formal potential of redox couple remains unchanged and there was no significant change in the peak current in the $1-5 \mathrm{pH}$ range. There after decrease in the peak current with increase in $\mathrm{pH}$ value was observed and peaks were completely disappeared at $\mathrm{pH}$ 8. This may be explained due to interaction between the hydroxyl ions in the solution and the metal ions 
Table 1

Interference study of cations, anions and organic acids generally present in food and water samples.

\begin{tabular}{lc}
\hline Interferents & Tolerance limit $(\mathrm{ppm})$ \\
\hline $\mathrm{Na}^{+}, \mathrm{K}^{+}, \mathrm{SO}_{4}{ }^{2-}, \mathrm{CO}_{3}{ }^{2-}, \mathrm{CI}^{-}$, citric, tartaric acid & 1000 \\
Glucose, fructose, sucrose & 1000 \\
Oxalic acid & 200 \\
Lactic acid & 100 \\
Bromide & 300 \\
Nitrate & 1000 \\
Nitrite & 15 \\
Nitrite & 200 \\
\hline
\end{tabular}

a Sample was treated with $3 \mathrm{ml}$ of $2 \%$ sulfamic acid before its electrochemical measurement.

of the complex in the electrode to form the metal hydroxides. Hence $\mathrm{pH}$ of the electrolyte solution was maintained at 5 throughout the studies.

\subsubsection{Effect of supporting electrolyte}

The electrolyte cations play an important role on the electrochemical behavior of CoNP and its analogues. Electrolyte cations enter or leave the MNP surface to maintain the electroneutrality of the metal nitroprussides during the electrochemical process. Effect of alkali metal cations have been well studied on the electrochemical behavior of CoNP [49]. We have examined the effect of $\mathrm{Li}^{+}$, $\mathrm{Na}^{+}$and $\mathrm{K}^{+}$cations by using their respective salt solutions at $0.5 \mathrm{M}$ concentration. Well defined peaks with high peak current values were observed in case of potassium nitrate. Therefore $0.5 \mathrm{M} \mathrm{KNO}_{3}$ was used as an electrolyte in the further electrochemical investigations of n-CoNP CPE for sulfite quantification using the proposed electrochemical sensor.

\subsection{Interference study}

The suitability of the developed electrochemical sensor mainly depends on the effect of interfering species present in the real samples along with the analyte. In order to apply the developed sensor for real sample analysis the effect of common interferents that are present in various food samples were studied by spiking these species in the form of its corresponding salts. The organic acids such as ascorbic acid, lactic acid, citric acid, tartaric acid and oxalic acid, sugars such as glucose, fructose, sucrose and some inorganic ions such as bromide, chloride, nitrite, sodium, potassium, carbonate, sulfate were studied at different concentration level. The tolerance limits of common interferents are listed in Table 1. Among the interfering species studied, nitrite interfered seriously even at $15 \mathrm{ppm}$ level causing more than $\pm 2 \%$ error which was overcome by treating the sample with $3 \mathrm{ml}$ of $2 \%$ sulfamic acid. Sulfamic acid reacts with nitrite and converts it to nitrogen. Majority of the species did not interfere even at 100 -fold excess.

\subsection{Calibration plot}

Eight $\mathrm{ml}$ of $0.5 \mathrm{M}$ potassium nitrate solution was transferred into a three electrode $10 \mathrm{ml}$ electrochemical cell. The initial and final potentials were adjusted to $0-1.0 \mathrm{~V}$ vs. $\mathrm{Ag} / \mathrm{AgCl}$ respectively and the voltammograms were recorded at a scan rate of $0.5 \mathrm{~V} \mathrm{~s}^{-1}$. The experiment was repeated in presence of sulfite at different concentrations and the increase in peak current values were proportional to the sulfite concentration (Fig. 9). A calibration graph was constructed by plotting the peak currents vs. the sulfite concentration. A linear response was obtained in the concentration range $1-5.9 \times 10^{-5} \mathrm{M}$ as well as $2-8 \times 10^{-3} \mathrm{M}$. The standard deviation (SD) and regression coefficient $\left(r^{2}\right)$ values were found to be $0.011,0.250$ and $0.998,0.98$ for lower and higher end calibration
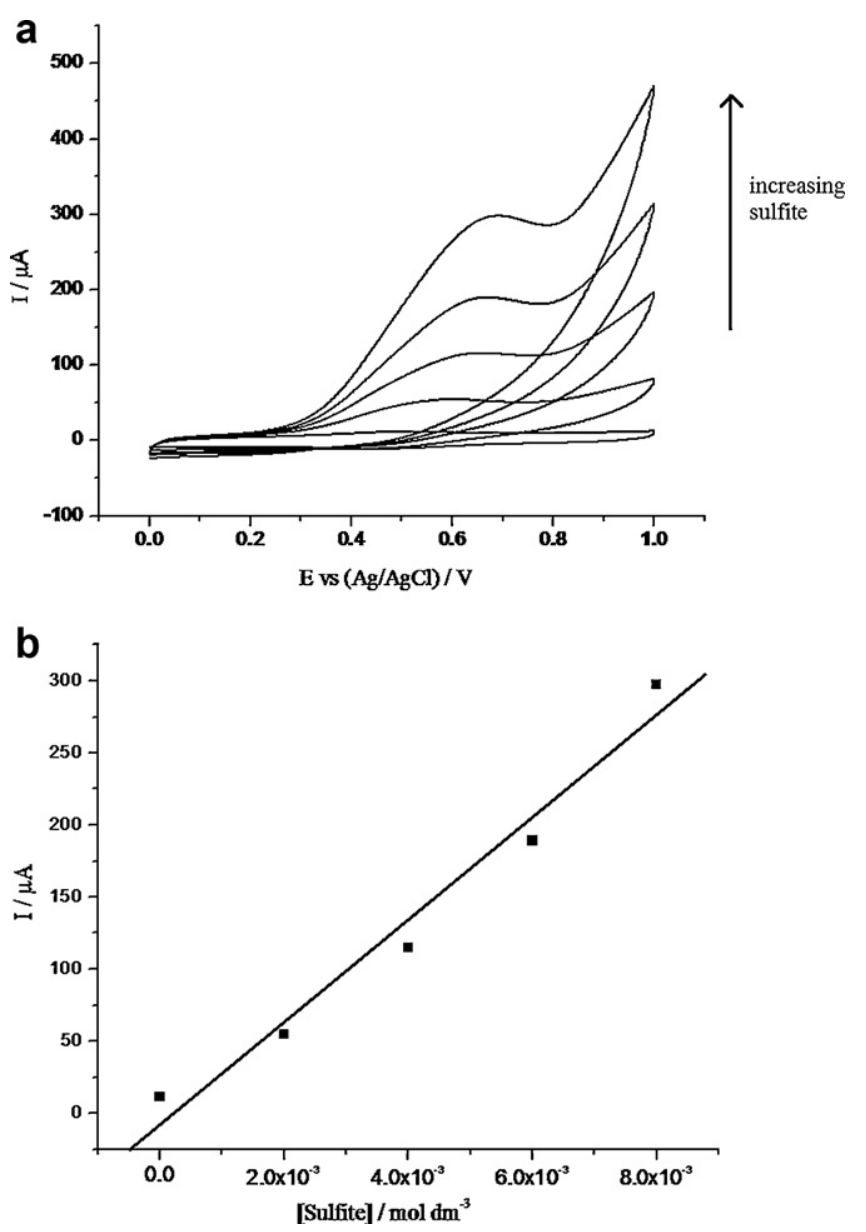

Fig. 9. (a) Overlaid voltammograms of $n$-CoNP CPE in presence of $0,2,4,6,8 \mathrm{mM}$ sulfite concentrations in $0.5 \mathrm{M} \mathrm{KNO}_{3}$ as electrolyte at scan rate $0.5 \mathrm{~V} \mathrm{~s}^{-1}$ and (b) calibration graph was constructed by plotting obtained current response vs. sulfite concentration.

graphs respectively. Linear regression equations $Y=1.409+8.586 X$ and $Y=-0.071+0.331 X$ are obtained for the lower and higher end calibration graph respectively. The limit of detection (LOD) and limit of quantification (LOQ) were found to be $0.4 \times 10^{-5} \mathrm{M}$ and $2.29 \times 10^{-5} \mathrm{M}$ respectively for the lower end calibration graph.

\subsection{Application study}

The applicability of the proposed electrochemical sensor has been examined by measuring the sulfite content from a variety of food stuff sample matrices such as dry fruits, sugar, wine and water samples. Various sample solutions were prepared following the standard procedure and analyzed by the proposed electrochemical sensor as well as standard iodometric method [50]. The validity of the proposed method has been checked by the recovery study. Known concentrations of sulfite were spiked with the samples and total sulfite content was analyzed.

\subsubsection{Sugar samples}

Commercially available $25 \mathrm{~g}$ of sugar sample was dissolved in distilled water and made up to $100 \mathrm{ml}$. One $\mathrm{ml}$ aliquot of sugar solution was analyzed by the proposed electrochemical sensor.

\subsubsection{Dried grapes}

Ten grams of dried grapes were taken in a $250 \mathrm{ml}$ beaker and soaked by adding $25 \mathrm{ml}$ of $2 \mathrm{M} \mathrm{NaOH}$ solution. After $30 \mathrm{~min}$ the grapes were smashed gently using glass rod then it was allowed to 
Table 2

Determination of sulfite in food and water samples.

\begin{tabular}{|c|c|c|c|c|c|c|}
\hline \multirow[t]{2}{*}{ Sample } & \multicolumn{3}{|c|}{ Proposed method } & \multirow[t]{2}{*}{ Standard method } & \multicolumn{2}{|l|}{ Recovery (\%) } \\
\hline & Original sulfite & Added sulfite & Total sulfite & & Proposed method & Standard method \\
\hline Sugar $^{\mathrm{a}}$ & $19 \pm 2.3$ & 10 & $28.8 \pm 1.9$ & $30.1 \pm 1.8$ & 97.2 & 102.7 \\
\hline Dry grapes ${ }^{\mathrm{a}}$ & $19.5 \pm 2.1$ & - & - & $19.2 \pm 2.3$ & - & \\
\hline Wine $^{\mathrm{b}}$ & $12.3 \pm 2.1$ & 10 & $21.8 \pm 2.0$ & $22.6 \pm 1.5$ & 97.7 & 101.8 \\
\hline Tap water ${ }^{\mathrm{b}}$ & - & 7.5 & $7.4 \pm 2.0$ & $7.5 \pm 1.9$ & 98.6 & 100.0 \\
\hline Drinking water ${ }^{\mathrm{b}}$ & - & 3.7 & $3.8 \pm 1.9$ & $4.0 \pm 1.8$ & 102.7 & 108.1 \\
\hline
\end{tabular}

All the values are average of the three measurements \pm RSD.

a Concentration of sulfite is expressed in $\mathrm{mg} / 100 \mathrm{~g}$.

b Concentration of sulfite is expressed in $\mathrm{mg} / 100 \mathrm{ml}$.

stand for $2 \mathrm{~h}$. The contents in the beaker were thoroughly mixed and filtered quantitatively using whatman filter paper. The filtrate was neutralized by concentrated sulfuric acid and the $\mathrm{pH}$ was adjusted to 5 and the solution was made up to known volume. One $\mathrm{ml}$ of the diluted filtrate was used for the analysis by the proposed method by following the procedure described as above.

\subsubsection{Wine and water samples}

White wine and water samples were also analyzed for sulfite content without any pretreatment. 0.5 and $1.0 \mathrm{ml}$ volumes of wine and water samples were analyzed by the proposed method.

Sulfite in all the above samples has been quantified using the standard iodometric method by taking the suitable volume of aliquot from the samples.

The results obtained by the proposed electrochemical and standard iodometric method have been shown in Table 2 . There is a good agreement in the results obtained by the proposed method and the iodometric method.

\section{Conclusions}

We have proposed a simple methodology to prepare CoNP nano particles without the use of any additives. The nano CoNP complex was characterized by SEM, FTIR, XRD and CV study. The synthesized CoNP nanoparticles were used as an indicator species toward the electrocatalytic oxidation of sulfite in the form of modified carbon paste electrode. The n-CoNP CPE showed a considerably enhanced electrocatalytic activity in presence of sulfite when compared to s-CoNP and b-CoNP. The n-CoNP modified CPE exhibits one electron transfer process with heterogeneous EC catalytic mechanism. A linear response was obtained in the concentration range $1-5.9 \times 10^{-5} \mathrm{M}$ as well as $2-8 \times 10^{-3} \mathrm{M}$. The limit of detection(LOD) and limit of quantification (LOQ) were found to be $0.4 \times 10^{-5} \mathrm{M}$ and $2.29 \times 10^{-5} \mathrm{M}$ respectively for the lower end calibration graph. Modified CPE showed the linear range and detection limit comparable $[25,26]$ and better $[51-53]$ than the reported electrochemical methods.

\section{Acknowledgements}

The authors acknowledge the financial support and award of Senior Research Fellowship (SRF) to Samrat Devaramani by the Council of Scientific \& Industrial Research (CSIR), New Delhi, India.

\section{References}

[1] L.M. Baraldo, P. Forlano, A.R. Parise, L.D. Slep, J.A. Olabe, Coordination Chemistry Reviews 219-221 (2001) 881

[2] L.L. Paim, N.R. Stradiotto, Electrochimica Acta 55 (2010) 4144.

[3] H. Razmi, H. Heidari, Analytical Biochemistry 388 (2009) 15.

[4] Z. Xun, C. Cai, T. Lu, Electroanalysis 16 (2004) 674.

[5] C.X. Cai, K.H. Xue, S.M. Xe, Journal of Electroanalytical Chemistry 486 (2000) 111.
[6] D.M. Zhou, H.X. Ju, H.Y. Chen, Journal of Electroanalytical Chemistry 408 (1996) 219.

[7] H. Razmi, E. Habibi, Analytical Biochemistry 392 (2009) 126.

[8] H. Razmi-Nerbin, M. Hossaini Sadr, B. Habibi-A, Journal of Electroanalytical Chemistry 574 (2005) 207.

[9] H. Razmi, K. Heidari, Electrochimica Acta 50 (2005) 4048.

[10] M.H. Pournaghi-Azar, H. Nahalparvari, Journal of Electroanalytical Chemistry 583 (2005) 307

[11] A. Salimi, K. Abdi, G.R. Khayatiyan, Electrochimica Acta 49 (2004) 413.

[12] M.H. Pournaghi-Azar, M. Hydarpour, H. Dastangoo, Analytica Chimica Acta 497 (2003) 133.

[13] K. Kalcher, J.M. Kauffmann, J. Wang, I. Svancara, K. Vytras, C. Neuhold, Z. Yang Electroanalysis 7 (1995) 23.

[14] R.C. Ashoori, Nature 379 (1996) 413.

[15] M. Yoshinaga, H. Takahashi, K. Yamamoto, A. Muramatsu, T. Morikawa, Journa of Colloid and Interface Science 309 (2007) 149.

[16] J.M. Domynguez-Vera, E. Colacio, Inorganic Chemistry 42 (2003) 6983.

[17] S. Vaucher, J. Fielden, M. Li, E. Dujardin, S. Mann, Nano Letters 2 (2002) 225.

[18] S.Q. Liu, J.J. Xu, H.Y. Chen, Electrochemistry Communications 4 (2002) 421.

[19] F. Valentini, A. Amine, S. Orlandocci, M.L. Terranova, G. Palleschi, Analytica Chemistry 75 (2003) 5413.

[20] A. Antiochia, I. Lavagnini, F. Magno, F. Valentini, G. Palleschi, Electroanalysis 1 (2004) 1451.

[21] A. Isaac, C. Livingstone, A.J. Wain, R.G. Compton, J. Davis, Trends in Analytical Chemistry 25 (2006) 589.

[22] FDA, Federal Register 51 (July (131)) (1986) 25021

[23] Gunnison, Jacobsen, CRC Critical Reviews in Toxicology 17 (1987) 185.

[24] M.R. Lester, Journal of the American College of Nutrition 14 (1995) 229.

[25] C. Chinvongamorn, K. Pinwattana, N. Praphairaksit, T. Imato, O. Chailapakul Sensors 8 (2008) 1846.

[26] H. Zhou, W. Yang, C. Sun, Talanta 77 (2008) 366.

[27] A. Siroueinejad, A. Abbaspour, M. Shamsipur, Electroanalysis 21 (2009) 1387.

[28] A.A. Ensafi, H.K. Maleh, International Journal of Electrochemical Science 5 (2010) 392.

[29] L. Shayne, T. Alamoa, T. Tangkuarama, S. Satienperakula, Talanta 81 (2010) 1793.

[30] T.R.L. Dadamos, M.F.S. Teixeira, Electrochimica Acta 54 (2009) 4552.

[31] A. Safavi, N. Maleki, S. Momeni, F. Tajabadi, Analytica Chimica Acta 625 (2008)

[32] A.A. Ensafi, H.A. Soleymani, E. Mirmomtaz, Microchemical Journal 89 (2008) 108.

[33] Ü.T. Yilmaz, G. Somer, Analytica Chimica Acta 603 (2007) 30.

[34] R. Spricigoa, C. Richtera, S. Leimkühlera, L. Gortonb, F.W. Schellera, U. Wollenbergera, Colloids and Surfaces A: Physicochemical and Engineering Aspects 354 (2010) 314.

[35] M. Iammarino, A. Di Taranto, M. Muscarella, D. Nardiello, C. Palermo, D. Centonze, Analytica Chimica Acta 672 (2010) 61.

[36] L.Q. Yin, D.X. Yuan, M. Zhang, Chinese Chemical Letters 21 (2010) 1457.

[37] S. Satienperakul, P. Phongdong, S. Liawruangrath, Food Chemistry 121 (2010) 893.

[38] M.V. Navarrro, M.R. Payán, M.A.B. López, R. Fernández-Torres, M.C. Mochón, Talanta 82 (2010) 2003.

[39] P.D. Tzanavaras, E. Thiakouli, D.G. Themelis, Talanta 77 (2009) 1614.

[40] M.H. Pouranghi-Azar, R.E. Sabzi, Electroanalysis 16 (2004) 860.

[41] S.P. Moulik, G.C. De, A.K. Panda, B.B. Bhowmik, A.R. Das, Langmuir 15 (1999) 8361.

[42] S. Vaucher, M. Li, S. Mann, Angewandte Chemie International Edition 39 (2000) 1793.

[43] L. Catala, T. Cacoin, J.P. Biolot, E. Riviere, C. Paulsen, E. Hotel, T. Mallah, Advanced Materials 15 (2003) 826.

[44] G. Clavel, J. Larinova, Y. Gauri, C. Guerin, Inorganica Chimica Acta 361 (2008) 3988.

[45] E. Chelevaeva, Y. Guri, J. Lrinova, A. Trifonov, C. Guerin, Chemistry of Materials 20 (2008) 1367.

[46] L. Shi, T. Wu, M. Wang, D. Li, Y. Zhang, J. Li, Chinese Journal of Chemistry 23 (2005) 149.

[47] M. Berrettoni, M. Giorgetti, S. Zamponi, P. Conti, D. Ranganathan, A. Znotto, M.L. Saladino, E. Caponeti, Journal of Physical Chemistry C 114 (2010) 6401.

[48] H. Razmi, R. Mohmmad-Rezaei, Microchimica Acta 171 (2010) 257 
[49] M.H. Pournaghi-Azar, R. Sabzi, Journal of Electroanalytical Chemistry 543 (2003) 115.

[50] A.E. Greenberg, L.S. Clesceri, A.D. Eaton, Standard Methods for the Examination of Water and Waste Water, 18th ed., American Health Association, Washington, DC, 1992.
[51] J.B. Raoof, R. Ojani, H. Karimi-Maleh, International Journal of Electrochemical Science 2 (2007) 257.

[52] J.B. Raoof, R. Ojani, H. Karimi-Maleh, Asian Journal of Chemistry 20 (2008) 483

[53] T. Garcia, E. Casero, E. Lorenzo, F. Pariente, Sensors and Actuators B 106 (2005) 803. 